\title{
Review Article: \\ Complications of Halo Vest Orthosis: A Narrative Study
}

\author{
Ali Babashahi ${ }^{1}$, Majid Rezvani ${ }^{2} Q$, Majid Vatankhah ${ }^{3}$, , Navid Kalani ${ }^{4}$, Ali Kazeminezhad ${ }^{5^{*}} \mathrm{G}$
}

1. Department of Neurosurgery, School of Medicine, Hazrat-e Rasool General Hospital, Iran University of Medical Sciences, Tehran, Iran 2. Department of Neurosurgery, School of Medicine, Neurosciences Research Center, Al-Zahra Hospital, Isfahan University of Medical Sciences, Isfahan, Iran 3. Anesthesiology and Critical Care and Pain Management Research Center, Hormozgan University of Medical Sciences, Bandar Abbas, Iran 4. Anesthesiology, Care and Pain Management Research Center, Jahrom University of Medical Sciences, Jahrom, Iran

5. Department of Neurosurgery, Peymanieh Hospital, Jahrom University of Medical Sciences, Shiraz, Iran

$\begin{gathered}\text { Use your device to scan } \\ \text { and read the artice online }\end{gathered}$
Study. Iran J Neurosurg. 2021; 7(3):131-138. http://dx.doi.org/10.32598/irjns.7.3.2
d.t: : http://dx.doi.org/10.32598/irjns.7.3.2

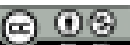

Article info:

Received: 19 Jan 2021

Accepted: 13 May 2021

Available Online: 01 Jul 2021

Keywords:

Halo vest, Immobilization, Fractures, Spine, Cervical vertebrae

\section{ABSTRACT}

Background and Aim: Perry and Nickel introduced the halo vest in 1959. It is the most common immobilization device for the unstable cervical spine. In the literature review, most articles review the beneficial effects of the halo vest, and a few report its complications. This study aims to evaluate the complications associated with halo orthosis.

Methods and Materials/Patients: This is a narrative study about halo vest complications. To provide up-to-date information, we reviewed the articles written about halo complications. All relevant articles were retrieved from Google Scholar, Medline, PubMed, etc., using the keywords of "halo vest orthosis", "unstable cervical spine fracture", "halo vest complications", "halo vest immobilization", "pin-site-related complications", and "vest-related complications". Afterward, we reviewed and critically analyzed the articles.

Results: At first, the halo vest was used for postoperative paralyzed poliomyelitis patients, and later, it was also used for traumatic injury of the cervical spine or postoperatively in cervical spine reconstructive surgery. Compared to other orthoses, the halo vest provides a more effective external fixation and maintains normal anatomic alignment of the cervical spine without impacting jaw motion and resulting in eating problems. However, it has many temporary complications. To prevent halo vest complications, experienced people should apply it, and the patients should be regularly followed up for early detection and treatment of complications.

Conclusion: Our review is the starting point for the evaluation and investigation of halo vest complications. Because of the high incidence of pin loosening and infection, it is better to evaluate the design and application of halo pin. Since the initial design of the halo vest, only its superstructure has been redesigned without any significant change in other parts of it.

\section{* Corresponding Author:




\section{Highlights}

- Halo vest orthosis is used for cervical spine fractures.

- The most common complications of halo vest orthosis are pin-site related infections and loosening.

- There are many complications of halo vest that are related to halo vest placement.

\section{Plain Language Summary}

Halo vest orthosis is used for variable cervical spine fractures. In this narrative study, we review the complications of halo vest orthosis. It has many different complications. The most common complications are related to pin-site infection and loosening. Some complications are related to halo vest orthosis placement.

\section{Introduction}

bout $60 \%$ of spinal injuries occur in the A cervical spine, and $20 \%$ of its fractures occur in the upper cervical spine. We can use different orthoses such as halo vest, Minerva, CTLSO (cervicothoracic lumbosacral orthosis), etc., for nonoperative treatment of cervical spine fractures. In many centers, the halo vest is the first choice for nonsurgical treatment and external fixation. However, the halo vest has some complications (with a relatively high rate). So for the usage of the halo vest in these conditions, we must consider these disadvantages. We conducted this study to evaluate the associated complications of halo vest immobilization [1-10].

Halo vest can protect against neurological damage in posttraumatic cervical spine instability. Still, because of incomplete immobilization, there is a chance of progressive deformity that may result in surgical treatment for spinal instability. Also, restriction of halo vest for three months is not tolerable for some patients [11]. Complications of halo vest are relatively high and include pin loosening, migration, penetration, scalp infection, skull fracture, cerebral hemorrhage, paresthesia, and pressure sores [12]. The fracture healing rates with halo vest in the cervical spine are about $67 \%$ to $93.9 \%$ [13-15]. Overall, the halo vest has a failure rate of $39.1 \%$, with complications in $60.9 \%$ of patients and an intolerability rate of $68.4 \%$. Pin-site problems are the most prevalent complications of halo. Because of the many complications and high failure rate of halo vest immobilization, the clinicians must rethink before applying halo. To prevent these problems, physicians must consider pin-site problems for early detection and treatment [15]. This narrative study aims to evaluate and search the rate and type of complications of halo vest orthosis.

\section{Methods and Materials/Patients}

This article is a narrative study about the halo vest complications. To provide up-to-date information on the complications of the halo vest, we briefly reviewed its complications in related articles. We retrieved all relevant articles from Google Scholar, Medline, PubMed, etc. using the keywords of "halo vest orthosis", "unstable cervical spine fracture", "halo vest complications", "halo vest immobilization", "pin-site-related complications", and "vest-related complications". Finally, the extracted papers were reviewed and critically analyzed.

\section{Results}

The halo vest is a rigid orthosis with a ring and four pins attached to the outer cortex of the cranium. It has a complication rate of $0 \%-100 \%$ because of its rigid ring that attaches to the outer cortex of the cranium. We briefly reviewed the halo complications and classified them based on the etiology (pin, vest, underlying pathology, etc.) of complications.

\section{Pin-related complications}

Pin loosening: This is the most prevalent complication in adults, occurring in as many as $36 \%$ of patients. In adults, loosening is slightly more common with anterior pins than with posterior pins. In children, anterior pin loosening also is predominant, occurring in up to $87 \%$ of cases. A loose pin without signs of infection can be retightened one to two turns. When the pin remains loose after this maneuver, a new pin should be placed in another location. It is essential to place the new pin 
within the safe zone $[16,17]$. The loose pin must be retightened, but if loosening is not fixed, the pin must be removed and placed in another location [18]. Loosening is considered when any of the following conditions occur: first, if a pin is freely twisted and moved by the examiner without any restriction or pin tip is visible at the edge of the skin rather than at the edge of the skull. In these circumstances, first of all, tighten the loosened pins. If there is some resistance during tightening of the pin, there is no need for its removal. However, the pin must be removed and placed in another location if there is no resistance to the pin turning [3].

Supraorbital and supratrochlear nerve palsy: Ideal pin-site placement for anterior pins prevent this complication. If anterior pins of the halo vest are inserted at the medial third part of the eyebrow, there is a high risk of damage to the supraorbital and supratrochlear nerve. This complication clinically manifests with pain and paresthesia in the forehead area above the anterior pins. After removing anterior pins and changing the pinsite area at the more lateral position, the patient's clinical manifestations should be improved [3].

Pin-site bleeding: In patients who require anticoagulant therapy while using a halo device, pin-site bleeding must be considered [3].

Pin scars: [3].

Pin discomfort: Severe pin discomfort is reported in $18 \%$ of patients with a halo vest [3].

Pin-site infection: Pin-site infection is more prevalent in children than adults, with reported rates between $39 \%$ and $57 \%$. There are two types of pin-site infections: superficial infections that may not be associated with pin loosening and deep infections that may be associated with osteomyelitis or rarely intracranial abscess.

Diagnosis of infection is initially based on the presence or absence of cellulitis at the pin-site and then positive or negative culture results. Superficial infections can be treated with oral antibiotics (e.g., oral cephalosporin), with or without pin removal, but deep infections require pin removal with a new pin at a new site, debridement, and systemic antibiotics. If the infection is resistant to treatment with permanent drainage, cellulitis, or other signs of infection, the pin-site must be changed and placed in another location with the initiation of more potent local and possibly intravenous antibiotic therapy.
Regarding the prevention, at the initial stage for pins placement, all pins must be inserted under aseptic conditions. After pin insertion, they must be cleaned every other day with betadine or hydrogen peroxide at a hospital and after discharge at home. Because of low-grade infection, more frequent cleansing is not suitable. The risk of infection in anterior pins is more than other pins without any known reasonable cause. The usefulness of wound cultures is not known, and these cultures are not part of routine practice. Nemeth and Mattingly reported that a six-pin construct increased stability without increasing the rate of pain-related complications; however, this is currently not considered standard practice in adults [16-19].

Overpenetration of pins: Skull has an outer and inner table, and all pins must only penetrate the outer table. If pins traverse through the inner table of the skull, they cause dural puncture, and if infection occurs, it can cause a brain abscess. Titanium conical pins are gradually blunted. Even newly replaced pins can be blunted in four weeks. Reusing halo rings and vests after cautious examination to rule out any defect is possible, but reuse of skull pins should be avoided. Pin loosening can occur because of microfractures and creep of the outer cortex of the skull around the pin tip after insertion of conical pins. The risk of pin loosening and penetration to the inner cortex increases whenever a blunt or hooked pin tip is rotated during the checking of poundage or routine re-torquing. The routine practice of re-torquing skull pins beyond three weeks should be revised. Whenever patients have pin-site pain, and the pin tip is deformed, it should be changed rather than re-torquing $[20,21]$.

Pneumocranium: If pins penetrate the frontal sinus, pneumocranium occurs. Halo vest anterior pins must be placed at about $1 \mathrm{~cm}$ superior to the orbital rim and at the lateral half of the eyebrow for preventing frontal sinus penetration and supraorbital and supratrochlear nerve injury. However, there is a variation of normal anatomic landmarks of the frontal sinus, and these typical anatomic landmarks for halo vest pin placement are not always safe, especially on the left side, in which the frontal sinus is potentially larger. So it is obligatory to take a skull x-ray with a marker in the pin insertion area or CT-scan of the skull and frontal sinus before halo vest pin placement. Furthermore, tactile evaluation during insertion is critical to detect penetration. If there is a loss of resistance during pin insertion, the surgeon must consider potential cranial penetration and pneumocranium $[22,23]$.

Pin-site myiasis: Maggots are parasites and are classified into two types of obligatory and facultative. Obligatory maggots are invasive and affect the living tissue, but 
facultative consume the necrotic dead tissue. It most commonly affects the lower limbs ulcer and wounds with necrotic dead tissues. Based on Park et al., because of the dead necrotic tissue around the pin, pin-site myiasis can occur. For effective improvement of this complication, maggots must be completely removed [24-27].

Brain abscess: This is a rare fatal complication of halo vest. Overpenetration of pins that traverse through the inner skull table and enter the cranium increase the risk of intracranial infections. Standard correct pin-site placement is crucial to prevent minor complications with resulting cerebral abscess. So, it is better to avoid pin placement at the temporalis muscle area. Pins are designed with a broader body and sharp tip to prevent overpenetration through the inner table. As mentioned, it is better to avoid pin placement in the temporalis muscle area because it is painful, causes difficulty in chewing, and underlying bone is thin and susceptible to puncture and overpenetration. The ideal good position for posterior pins is at the area of the 4 and 8 o'clock of calvaria as 12 o'clock is glabella, and 6 o'clock is occipital protuberance.

Due to the difficulty of achieving firm pin placement, the use of halo traction devices must be prohibited in the following cases because of the loose pin placement: prior craniotomy, recent skull fractures, and soft bone as in Rheumatoid Artheritis (RA) or multiple myeloma. All pins must be retightened 24 hours after pin placement and then after one week and again during 4-6 weeks follow-up periods. Delayed and excessive pin tightening must be prevented because of the pin overpenetration. If the patient has purulent discharge with or without neurological complaints, a brain CT scan must be done.

For detection of brain abscess in early stages, in all patients with halo device and neurological manifestations in favor of cerebritis or brain abscess, brain CT with contrast must be done immediately. Early recognition is mandatory because, at an earlier stage with only cerebritis, intravenous antibiotic treatment will be more effective. However, a well-developed abscess at the late stage has a firm fibrous capsule with necrotic material and debris resistant to parenteral antibiotic therapy. So the only available option for treatment is surgical evacuation followed by antibiotic treatment. Following pin penetration through the inner table with continuous pressure and irritation of the dural surface and an associated inflammatory process, infectious organisms enter into the subdural space. Deeper cerebral abscesses can occur because of retrograde thrombophlebitis through the dural veins with halo fixation devices [28-36].
Infectious cavernous sinus thrombosis: Infectious Cavernous Sinus Thrombosis (CST) was initially reported as an uncommon complication of facial infections. Infectious CST is an invasive infectious condition with a high fatality rate. Rahimizadeh et al. reported a case of septic CST secondary to a halo pin-site infection. In this case, CST occurred because of unrecognized pin-site infection and presented with proptosis and ipsilateral eyelid edema; however, with early consideration of CST and aggressive antibiotic and anticoagulant therapy, the patient had a favorable outcome [37-44].

Orbital roof fracture and orbital cellulitis: It is a rare halo complication caused by pin penetration into the orbit. It is followed by the inflammation of extraocular muscles and other orbital soft tissue, and this causes severe proptosis, ptosis, and diplopia. If anterior pins are placed too lateral and inferior, they can enter the orbit. The management is nonsurgical as parenteral antibiotics and topical antibiotic (ofloxacin eye drop) instillation into the eyes for ten days [45].

Acute subdural hematoma: This is a rare complication of the halo vest. To prevent this complication, it is obligatory to consider the bone quality, the patient's coagulation status, and other comorbidities [46].

\section{Vest-Related complications}

Pressure sores: This complication most commonly occurs in quadriplegic patients that have disordered skin sensation. Pressure sores commonly occur in the area of the scapula and sternum under the halo cast or vest. Early surgical stabilization with internal fixation effectively prevents pressure sores in patients with spinal cord injury [47-49].

Pulmonary complications: This is more common in older adults over 65 years with a halo vest. Because of reduced pulmonary compliance and following pulmonary infections, respiratory failure can mainly occur in the elderly with halo vests $[5,50]$.

\section{Problems related to original pathology}

Immobilization created by halo vest is not complete and absolute; thus, graft failure, implant migration, loss of reduction, over distraction, and snaking motion can occur. Rotation in opposite directions, hyperextension of the upper cervical spine, and hyperflexion of the subaxial cervical spine can cause snaking motion. This issue is especially prominent when the patient moves from prone to supine position. Therefore, the halo vest strap and pins must be checked and retightened. If this com- 
plication continues, consider a form-fitting cast vest. Snaking motion can cause inadequate healing and nonunion of the fractures/injured site [51, 52].

\section{Miscellaneous complications}

Abducens and trochlear nerve palsy: The most prevalent cranial nerve injury with halo is the sixth cranial nerve injury because of pin placement and traction. Because the sixth cranial nerve supply ipsilateral lateral rectus muscle, the patient presents with diplopia (double vision) and loss of the lateral gaze on the affected side. Watch and wait is the preferred treatment, and the condition will resolve itself. The fourth nerve palsy may be underreported because of masking by a coinciding sixth nerve palsy [53].

Transient hearing loss: [54].

Visual disturbances: [54].

Dysphagia: Overextension of the neck can cause dysphagia and improve with the halo adjustment [16]. Difficulty swallowing (dysphagia) occurs in $2 \%$ of the patients [55].

Failure to thrive (elderly): [56].

\section{Conclusions}

Based on this review, more evaluation and investigation about halo complications is obligatory, and our study delineates topics in need of further research. The most prevalent problems of the halo vest are pin loosening and infection, so it is better to change halo design and use. Halo vest cannot completely fix the cervical spine and prevent progressive deformity. Pin overpenetration is a serious complication of halo. For its prevention, only trained personnel with up-to-date information about the anatomy of this region can insert and place the halo in the right area. Regular exam after halo placement is obligatory for timely diagnosis and treatment of halo complications.

\section{Ethical Considerations}

Compliance with ethical guidelines

There were no ethical considerations to be considered.

Funding

This research did not receive any grant from funding agencies in the public, commercial, or non-profit sectors.

\section{Authors' contributions}

All authors equally contributed to preparing this article.

Conflict of interest

The authors declared no conflict of interest.

\section{Acknowledgements}

We would like to thank the Clinical Research Development Unit of Peymanieh Educational and Research and Therapeutic Center of Jahrom University of Medical Sciences for providing facilities to this work.

\section{References}

[1] Clark CR, White AA. Fractures of the dens. A multicenter study. The Journal of Bone and Joint Surgery. 1985; 67(9):13408. [DOI:10.2106/00004623-198567090-00006] [PMID]

[2] Nickel VL, Perry J, Garrett A, Heppenstall M. The halo. A spinal skeletal traction fixation device.The Journal of Bone and Joint Surgery. 1968; 50(7):1400-9. [DOI:10.2106/00004623196850070-00009] [PMID]

[3] Garfin SR, Botte MJ, Waters RL, Nickel VL. Complications in the use of the halo fixation device. The Journal of Bone and Joint Surgery. 1986; 68(3):320-5. [DOI:10.2106/00004623198668030-00002] [PMID]

[4] Lind B, Sihlbom H, Nordwall A. Halo-vest treatment of unstable traumatic cervical spine injuries. Spine. 1988; 13(4):425-32. [DOI:10.1097/00007632-198804000-00010] [PMID]

[5] Glaser JA, Whitehill R, Stamp WG, Jane JA. Complications associated with the halo-vest. A review of 245 cases. Journal of Neurosurgery. 1986; 65(6):762-9. [DOI:10.3171/ jns.1986.65.6.0762] [PMID]

[6] Guiot B, Fessler RG. Complex atlantoaxial fractures. Journal of Neurosurgery. 1999; 91(2 Suppl):139-43. [DOI:10.3171/ spi.1999.91.2.0139] [PMID]

[7] Kim DH, Vaccaro AR, Affonso J, Jenis L, Hilibrand AS, Albert TJ. Early predictive value of supine and upright $\mathrm{X}$-ray films of odontoid fractures treated with halo-vest immobilization. The Spine Journal. 2008; 8(4):612-8. [DOI:10.1016/j. spinee.2007.03.009] [PMID]

[8] Ochoa G. Surgical management of odontoid fractures. Injury. 2005; 36(Suppl 2):B54-64. [DOI:10.1016/j.injury.2005.06.015] [PMID]

[9] Rockswold GL, Bergman TA, Ford SE. Halo immobilization and surgical fusion: Relative indications and effectiveness in the treatment of 140 cervical spine injuries. The Journal of Trauma. 1990; 30(7):893-8. [DOI:10.1097/00005373-19900700000022] [PMID] 
[10] MajercikS, Tashjian RZ, Biffl WL, Harrington DT, Cioffi WG. Halo vest immobilization in the elderly: A death sentence? The Journal of Trauma. 2005; 59(2):350-6. [DOI:10.1097/01. ta.0000174671.07664.7c] [PMID]

[11] Glaser JA, Whitehill R, Stamp WG, Jane JA. Complications associated with the halo-vest. A review of 245 cases. The Journal of Trauma. 1986; 65(6):762-9. [DOI:10.3171/ jns.1986.65.6.0762] [PMID]

[12] Houtkin S, Levine DB. The halo yoke: A simplified device for attachment of the halo to a body cast. The Journal of Bone and Joint Surgery. 1972; 54(4):881-3. [DOI:10.2106/00004623197254040-00020] [PMID]

[13] Vieweg U, Schultheiss R. A review of halo vest treatment of upper cervical spine injuries. Archives of Orthopaedic and Trauma Surgery. 2001; 121(1-2):50-5. [DOI:10.1007/ s004020000182] [PMID]

[14] Fabris Monterumici DA, Sinigaglia R. Long term results of halovest fixation for upper cervical spine fractures. Chirurgia Narzadów Ruchu I Ortopedia Polska. 2007; 72(1):71-9. [PMID]

[15] Shin JJ, Kim SJ, Kim TH, Shin HS, Hwang YS, Park SK Optimal use of the halo-vest orthosis for upper cervical spine injuries. Yonsei Medical Journal. 2010; 51(5):648-52. [DOI:10.3349/ymj.2010.51.5.648] [PMID] [PMCID]

[16] Dormans JP, Criscitiello AA, Drummond DS, Davidson RS. Complications in children managed with immobilization in a halo vest. The Journal of Bone and Joint Surgery. 1995, 77(9):1370-3. [DOI:10.2106/00004623-199509000-00013] [PMID]

[17] Baum JA, EN Hanley Jr, Pullekines J. Comparison of halo complications in adults and children. Spine. 1989; 14(3): 251-2. [DOI:10.1097/00007632-198903000-00002] [PMID]

[18] Ebraheim N. Complications of the Halo Brace [Internet]. 2017 [12 May 2017]. Available from: mystrikingly.com/blog/ complications-of-the-halo-brace

[19] Nemeth JA, Mattingly LG. Six-pin halo fixation and the resulting prevalence of pin-site complications. The Journal of Bone and Joint Surgery. 2001; 83(3):377-82. [DOI:10.2106/00004623-200103000-00009] [PMID]

[20] Voor MJ, Anderson RC, Hart RT. Stress analysis of halo pin insertion by non-linear finite element modeling. Journal of Biomechanics. 1997; 30(9):903-9. [DOI:10.1016/S00219290(97)82887-4]

[21] Voor MJ, Khalily C. Halo pin loosening: A biomechanical comparison of experimental and conventional designs. Journal of Biomechanics. 1998; 31(4):397-400. [DOI:10.1016/S00219290(98)00029-3] [PMID]

[22] Tatlisumak E, Ovali GY, Asirdizer M, Aslan A, Ozyurt B, Bayindir P, et al. CT study on morphometry of frontal sinus. Clinical Anatomy. 2008; 21(4):287-93. [DOI:10.1002/ca.20617] [PMID]

[23] Tubbs RS, Elton S, Salter G, Blount JP, Grabb PA, Oakes WJ. Superficial surgical landmarks for the frontal sinus. Journal of Neurosurgery. 2002; 96(2):320-2. [DOI:10.3171/ jns.2002.96.2.0320] [PMID]

[24] Konkol KA, Longfield RN, Powers NR, Mehr Z. Wound myiasis caused by Cochliomyia hominivorax. Clinical Infectious Diseases. 1992; 14(1):366. [DOI:10.1093/clinids/14.1.366] [PMID]
[25] Sherman RA. Wound myiasis in urban and suburban United States. Archives of Internal Medicine. 2000; 160(13):2004-14. [DOI:10.1001/archinte.160.13.2004] [PMID]

[26] Kpea N, Zywocinski C. Flies in the flesh: A case report and review of cutaneous myiasis. Cutis. 1995; 55(1):47-8. [PMID]

[27] Park P, Lodhia KR, Eden SV, Lewandrowski KU, McGillicuddy JE. Pin-site myiasis: A rare complication of halo orthosis. Spinal Cord. 2005; 43(11):684-6. [DOI:10.1038/sj.sc.3101773] [PMID]

[28] Papagelopoulos PJ, Sapkas GS, Kateros KT, Papadakis SA Vlamis JA, Falagas ME. Halo pin intracranial penetration and epidural abscess in a patient with a previous cranioplasty: Case report and review of the literature. Spine. 2001; 26(19):E463-7. [DOI:10.1097/00007632-200110010-00030] [PMID]

[29] Quiñones-Hinojosa A, Chi JH, Manley GT. Emergent placement of halo orthosis after a traumatic cervical injury leading to a cerebral abscess. The Journal of Trauma. 2007; 62(6):E11-3. [DOI:10.1097/01.ta.0000246938.18656.5d] [PMID]

[30] Celli P, Palatinsky E. Brain abscess as a complication of cranial traction. Surgical Neurology. 1985; 23(6):594-6. [DOI:10.1016/0090-3019(85)90009-6]

[31] Dennis GC, Clifton GL. Brain abscess as a complication of halo fixation. Neurosurgery. 1982; 10(6 Pt 1):760-1. [DOI:10.1227/00006123-198206010-00017] [PMID]

[32] Goodman ML, Nelson PB. Brain abscess complicating the use of a halo orthosis. Neurosurgery. 1987; 20(1):27-30. [DOI:10.1097/00006123-198701000-00007] [PMID]

[33] Humbyrd DE, Latimer FR, Lonstein JE, Samberg LC. Brain abscess as a complication of halo traction. Spine. 1981; 6(4):365-8. [DOI:10.1097/00007632-198107000-00006] [PMID]

[34] Kameyama O, Ogawa K, Suga T, Nakamura T. Asymptomatic brain abscess as a complication of halo orthosis: Report of a case and review of the literature. Journal of Orthopaedic Science. 1999; 4(1):39-41. [DOI:10.1007/s007760050072] [PMID]

[35] Ray A, Iyer RV, King AT. Cerebral abscess as a delayed complication of halo fixation. Acta Neurochirurgica. 2006; 148(9):1015-6 [DOI:10.1007/s00701-006-0799-0] [PMID]

[36] Rosenblum D, Ehrlich V. Brain abscess and psychosis as a complication of a halo orthosis. Archives of Physical Medicine and Rehabilitation. 1995; 76(9):865-7. [DOI:10.1016/S00039993(95)80553-2] [PMID]

[37] Arian M, Kamali A, Tabatabaeichehr M, Arashnia P. Septic cavernous sinus thrombosis: A case report. Iranian Red Crescent Medical Journal. 2016; 18(8):e34961. [DOI:10.5812/ircmj.34961] [PMID] [PMCID]

[38] Colbert S, Cameron M, Williams J. Septic thrombosis of the cavernous sinus and dental infection. The British Journal of Oral \& Maxillofacial Surgery. 2011; 49(6):e25-6. [DOI:10.1016/j. bjoms.2010.07.004] [PMID]

[39] Ebright JR, Pace MT, Niazi AF. Septic thrombosis of the cavernous sinuses. Archives of Internal Medicine. 2001; 161(22):2671-6. [DOI:10.1001/archinte.161.22.2671] [PMID]

[40] Lizé F, Verillaud B, Vironneau P, Blancal JP, Guichard JP, Kania R, et al. Septic cavernous sinus thrombosis secondary to acute bacterial sinusitis: A retrospective study of seven cases. American Journal of Rhinology \& Allergy. 2015; 29(1):e7-12. [DOI:10.2500/ajra.2015.29.4127] [PMID] 
[41] Pannu AK, Saroch A, Sharma N. Danger triangle of face and septic cavernous sinus thrombosis. The Journal of Emergency Medicine. 2017; 53(1):137-8. [DOI:10.1016/j.jemermed.2017.03.016] [PMID]

[42] Visvanathan V, Uppal S, Prowse S. Ocular manifestations of cavernous sinus thrombosis. BMJ Case Reports. 2010; 2010:bcr0820092225. [DOI:10.1136/bcr.08.2009.2225] [PMID] [PMCID]

[43] Weerasinghe D, Lueck CJ. Septic cavernous sinus thrombosis: Case report and review of the literature. Neuroophthalmology. 2016; 40(6):263-76. [DOI:10.1080/01658107.2016.12301 38] [PMID] [PMCID]

[44] Rahimizadeh A, Williamson W, Rahimizadeh S, Asgari N Septic cavernous sinus thrombosis secondary to halo vest pinsite infection. North American Spine Society Journal. 2020; 4:100036. [DOI:10.1016/j.xnsj.2020.100036]

[45] Venugopal Menon $\mathrm{K}$, Al Rawi AE, Taif S, Al Ghafri K, Mollahalli KK. Orbital roof fracture and orbital cellulitis secondary to halo pin penetration: Case report. Global Spine Journal. 2015; 5(1):63-8. [DOI:10.1055/s-0034-1384818] [PMID] [PMCID]

[46] Medhkour.A, Medhkour A. Acute subdural hematoma following halo pin tightening in a patient with bilateral vertebral artery dissection. Neurochirurgie. 2012; 58(6):386-90. [DOI:10.1016/j.neuchi.2012.06.004] [PMID]

[47] Cooper PR, Maravilla KR, Sklar FH, Moody SF, Clark WK. Halo immobilization of cervical spine fractures, indications and results. Journal of Neurosurgery. 1979; 50(5):603-10. [DOI:10.3171/jns.1979.50.5.0603] [PMID]

[48] Kostuik JP. Indications for the use of the halo immobilization. Clinical Orthopaedics and Related Research. 1981; (154):46-50. [DOI:10.1097/00003086-198101000-00009] [PMID]

[49] Prolo DJ, Runnels JB, Jameson RM. The injured cervical spine, immediate and lont-term immobilization with the halo. JAMA. 1973; 224(5):591-4. [DOI:10.1001/jama.224.5.591] [PMID]

[50] Malik SA, Murphy M, Connolly P, O'Byrne J. Evaluation of morbidity, mortality and outcome following cervical spine injuries in elderly patients. European Spine Journal. 2008; 17(4):585-91. [DOI:10.1007/s00586-008-0603-3] [PMID] [PMCID]

[51] Bono CM. The halo fixator. The Journal of the American Academy of Orthopaedic Surgeons. 2007; 15(12):728-37. [DOI:10.5435/00124635-200712000-00006] [PMID]

[52] Ivancic PC, Telles CJ. Neck motion due to the halo-vest in prone and supine positions. Spine. 2010; 35(10):E400-6. [DOI:10.1007/978-3-642-14515-5_145] [PMID]

[53] Pinches E, Thompson D, Noordeen H, Liasis A, Nischal KK. Fourth and sixth cranial nerve injury after halo traction in children: A report of two cases. Journal of AAPOS. 2004; 8(6):580-5. [DOI:10.1016/j.jaapos.2004.08.002] [PMID]

[54] Hayes VM, Silber JS, Siddiqi FN, Kondrachov D, Lipetz JS, Lonner B. Complications of halo fixation of the cervical spine. The American Journal of Orthopedics. 2005; 34(6):271-6. [PMID]

[55] Rizzolo SJ, Piazza MR, Cotler JM, Hume EL, Cautilli G, O'Neill DK. The effect of torque pressure on halo pin complication rates. A randomized prospective study. Spine. 1993; 18(15):2163-6. [DOI:10.1097/00007632-199311000-00003] [PMID]
[56] Horn EM, Theodore N, Feiz-Erfan I, Lekovic GP, Dickman CA, Sonntag VK. Complications of halo fixation in the elderly. Journal of Neurosurgery: Spine. 2006; 5(1):46-9. [DOI:10.3171/ spi.2006.5.1.46] [PMID] 
This Page Intentionally Left Blank 